\title{
Production of Nanograined Intermetallics using High-pressure Torsion
}

\author{
Ali Alhamidi ${ }^{\mathrm{a} b}$, Kaveh Edalati ${ }^{\mathrm{a}, \mathrm{b}}$, Zenji Horita ${ }^{\mathrm{a}, \mathrm{b} *}$ \\ ${ }^{a}$ Department of Materials Science and Engineering, Faculty of Engineering, \\ Kyushu University, Fukuoka 819-0395, Japan \\ ${ }^{\mathrm{b}}$ WPI, International Institute for Carbon-Neutral Energy Research (WPI-I2CNER), \\ Kyushu University, Fukuoka 819-0395, Japan
}

Received: November 19, 2012; Revised: January 15, 2013

\begin{abstract}
Formation of intermetallics is generally feasible at high temperatures when the lattice diffusion is fast enough to form the ordered phases. This study shows that nanograined intermetallics are formed at a low temperature as $573 \mathrm{~K}$ in Al- $25 \mathrm{~mol} \% \mathrm{Ni}, \mathrm{Al}-50 \mathrm{~mol} . \% \mathrm{Ni}$ and $\mathrm{Al}-50 \mathrm{~mol} \%$ Ti powder mixtures through powder consolidation using high-pressure torsion (HPT). For the three compositions, the hardness gradually increases with straining but saturates to the levels as high as 550-920 Hv. In addition to the high hardness, the TiAl material exhibits high yield strength as $\sim 3 \mathrm{GPa}$ with good ductility as $\sim 23 \%$, when they are examined by micropillar compression tests. X-ray diffraction analysis and high-resolution transmission electron microscopy reveal that the significant increase in hardness and strength is due to the formation of nanograined intermetallics such as $\mathrm{Al}_{3} \mathrm{Ni}, \mathrm{Al}_{3} \mathrm{Ni}_{2}, \mathrm{TiAl}_{3}, \mathrm{TiAl}_{2}$ and TiAl with average grain sizes of $20-40 \mathrm{~nm}$.
\end{abstract}

Keywords: severe plastic deformation (SPD), ordering, phase transformation, micropillar, AlNi, TiAl, aluminide

\section{Introduction}

High-pressure torsion (HPT) was first introduced by Bridgman in 1935 to investigate the mechanical behavior and phase transformations in materials under high pressure and concurrent torsional straining ${ }^{1}$. The principle of the HPT processing is that a sample, in the form of disc or ring, is placed between two anvils which are rotated with respect to each other under application of compressive pressure, $P$, to create torsional strain, $\gamma$, in the sample ${ }^{2}$.

$\gamma=\frac{2 \pi r N}{t}$

where $r$ is the distance from the center of disc (or ring), $N$ is the number of turns and $t$ is the thickness of disc (or ring). In 1991, Valiev et al. reported the significance of grain refinement to the submicrometer and nanometer levels by $\mathrm{HPT}^{3}$. Over the last two decades, considerable interest has developed in processing materials through the application of HPT as a severe plastic deformation method not only for grain refinement ${ }^{4-6}$, but also for several other applications such as attainment of ultrahigh strength and high ductility ${ }^{7-9}$, attainment of high strength and high electrical conductivity ${ }^{10}$, achievement of high strength and high biocompatibility ${ }^{11-13}$, improvement of Tribocorrosion resistance ${ }^{14}$, improvement of wear resistance ${ }^{15}$, improvement of hydrogen storage capability ${ }^{16-18}$, achievement of photoluminescence effect ${ }^{19}$, controlling the allotropic phase transformations ${ }^{19-22}$, consolidation of machining chips $^{23,24}$, consolidation of metallic powders ${ }^{25-27}$, production

*e-mail: horita@zaiko.kyushu-u.ac.jp of supersaturated alloys ${ }^{28,29}$, and improvement of several other multifunctionalities ${ }^{30-32}$. Although most of these works are focused on HPT processing using bulk samples, consolidation of powders using HPT has recently received much attention ${ }^{23-30}$.

The HPT method was recently applied for production of nanostructured intermetallics with ultrahigh strength and high ductility from their elemental constituents ${ }^{33,34}$. The method was applied to powder mixtures of the Al-Ni and Al-Ti systems and it was found that in addition to powders consolidation and grain refinement, nanograined intermetallics were formed. This paper reports summary from the earlier study with additional results on the production of the nanograined $\mathrm{AlNi}$ and TiAl intermetallics ${ }^{33,34}$ and an extended application of the principle to an $\mathrm{Al}_{3} \mathrm{Ni}$ production from the $\mathrm{Al}$ and $\mathrm{Ni}$ elemental powders.

\section{Experimental Procedures}

Pure Al (99.99\%), Ni (99.99\%) and Ti $(99.9 \%)$ were received in the form of micropowders with particle sizes less than $75 \mu \mathrm{m}, 50 \mu \mathrm{m}$ and $150 \mu \mathrm{m}$, respectively. Powder mixtures of Al- 25\% Ni, Al- 50\% Ni and Al- 50\% Ti were prepared by mechanical agitation (all compositions are in mol\%). HPT was conducted at $573 \mathrm{~K}$ to consolidate the powder mixtures to discs with $10 \mathrm{~mm}$ diameter and $0.8 \mathrm{~mm}$ thickness under a pressure of $P=6 \mathrm{GPa}$. Shear strain was introduced through rotations for either $N=3,10,25,50$ or 120 turns with a rotation speed of $1 \mathrm{rpm}$. 
The HPT-processed discs were first polished to a mirror-like surface and Vickers microhardness was measured with an applied load of $200 \mathrm{~g}$ for $15 \mathrm{~s}$ along the radii at 8 different radial directions. Second, X-ray diffraction (XRD) analysis was performed using the $\mathrm{Cu} \mathrm{K} \alpha$ radiation in a scanning step of $0.01^{\circ}$ and a scanning speed of $0.5 \% \mathrm{~min}$. Third, for transmission electron microscopy (TEM), discs with $3 \mathrm{~mm}$ in diameter were cut from the HPT-processed discs at $3.5 \mathrm{~mm}$ away from the center. The $3 \mathrm{~mm}$ discs were ground to a thickness of $0.15 \mathrm{~mm}$ and further thinned for TEM with a solution of $10 \% \mathrm{H}_{2} \mathrm{SO}_{4}, 10 \% \mathrm{HNO}_{3}$ and $80 \%$ $\mathrm{CH}_{3} \mathrm{OH}$ at $263 \mathrm{~K}$ under an applied voltage of $18 \mathrm{~V}$ for the $\mathrm{Al}-\mathrm{Ni}$ samples and using a solution of $5 \% \mathrm{HClO}_{4}, 25 \%$ $\mathrm{C}_{3} \mathrm{H}_{3}\left(\mathrm{CH}_{2}\right)_{2} \mathrm{CH}_{2} \mathrm{OH}$ and $70 \% \mathrm{CH}_{3} \mathrm{OH}$ at $263 \mathrm{~K}$ under an applied voltage of $15 \mathrm{~V}$ for the Al-Ti samples. TEM was performed under a voltage of either $200 \mathrm{kV}$ or $300 \mathrm{kV}$ for microstructural observation and for recording selected-area electron diffraction (SAED) patterns. Fourth, the mirror-like surface of the HPT-processed samples was examined using scanning electron microscopy (SEM) under an applied voltage of $15 \mathrm{kV}$ to analyze the formation of micropores during HPT. Fifth, square-shaped micropillars with a side length of $\sim 4 \mu \mathrm{m}$ and a height of $\sim 12 \mu \mathrm{m}$ were prepared from the discs at $\sim 4 \mathrm{~mm}$ away from the center using focused ion beam (FIB) technique so that the side surfaces of the pillars become perpendicular to the disc surface ${ }^{34}$. Compression test was conducted on the micropillars using a microhardness testing machine equipped with a flat diamond tip with a diameter of $20 \mu \mathrm{m}$ at a nominal stress rate of $10 \mathrm{MPa} / \mathrm{s}$, which corresponds to an initial strain rate of $10^{-4} \mathrm{~s}^{-1}$. Sixth, the micropillars were observed by SEM under an applied voltage of $15 \mathrm{kV}$.

\section{Results and Discussion}

Figure 1 shows the hardness variation with the distance from the disc center after processing by HPT for various turns on the (a) Al- $25 \% \mathrm{Ni}$, (b) Al- $50 \% \mathrm{Ni}$ and (c) Al-50\% Ti samples. The microhardness increases with an increasing number of turns and an increasing distance from the disc center. The difference in the hardness behavior arises because the magnitude of strain created through HPT increases with increasing the turn and the distance from the disc center as given by Equation 1. The saturation of the hardness level is attained in the disc samples after 50 turns in the Al- $25 \% \mathrm{Ni}$ and after 10 turns in the Al- 50\% Ni and Al- $50 \% \mathrm{Ti}$, indicating that increasing the atomic fraction of the second element can accelerate the hardening during HPT. The hardness levels at the saturation, 550-920 Hv, exceeds those of most HPT-processed metals and alloys reported thus $\operatorname{far}^{2-7}$.

XRD profiles are shown in Figure 2 for the powder mixtures of (a) Al- 25\% Al, (b) Al- $50 \% \mathrm{Ni}$ and (c) Al-50\% $\mathrm{Ti}$ and for the corresponding compositions of discs consolidated by HPT for various turns. A close examination of Figure 2 indicates the four important points. First, the $\mathrm{Al}_{3} \mathrm{Ni}$ intermetallic is formed in the $\mathrm{Al}-25 \% \mathrm{Ni}$ after processing the powders by HPT, but a certain fraction of $\mathrm{Al}_{3} \mathrm{Ni}_{2}$ intermetallic are detected at large strains. The formation of intermetallics are controlled by atomic diffusion and it is well documented that the diffusivity can strongly be enhanced during severe plastic deformation because of the presence of large fractions of high-angle grain boundaries ${ }^{35,36}$ as well as because of supersaturation of vacancies ${ }^{37}$. Second, the $\mathrm{Al}_{3} \mathrm{Ni}$ intermetallics are formed at an early stage of straining in the Al- $50 \% \mathrm{Ni}$ sample, but they transform to $\mathrm{Al}_{3} \mathrm{Ni}_{2}$ intermetallic at large strains. Since the diffusion of $\mathrm{Ni}$ in $\mathrm{Al}$ is faster than the diffusion of $\mathrm{Al}$ in $\mathrm{Ni}^{38}$, the $\mathrm{Ni}$ atoms diffuse to the $\mathrm{Al}$ matrix and form the Al-rich $\mathrm{Al}_{3} \mathrm{Ni}$ intermetallics which then transforms to the $\mathrm{Al}_{3} \mathrm{Ni}_{2}$ intermetallics with further diffusion of $\mathrm{Ni}$ atoms. Third, large fractions of $\mathrm{TiAl}_{3}, \mathrm{TiAl}_{2}$ and $\mathrm{TiAl}$ intermetallics are formed in the $\mathrm{Al}-50 \% \mathrm{Ti}$ and their fraction increases with increasing strain. The $\mathrm{TiAl}_{3}$ cannot be detected at the steady state because the diffusivity of Ti in $\mathrm{TiAl}_{3}$ is rather fast ${ }^{38}$ and it transforms to the $\mathrm{TiAl}_{2}$ and $\mathrm{TiAl}$ intermetallics. Fourth, the
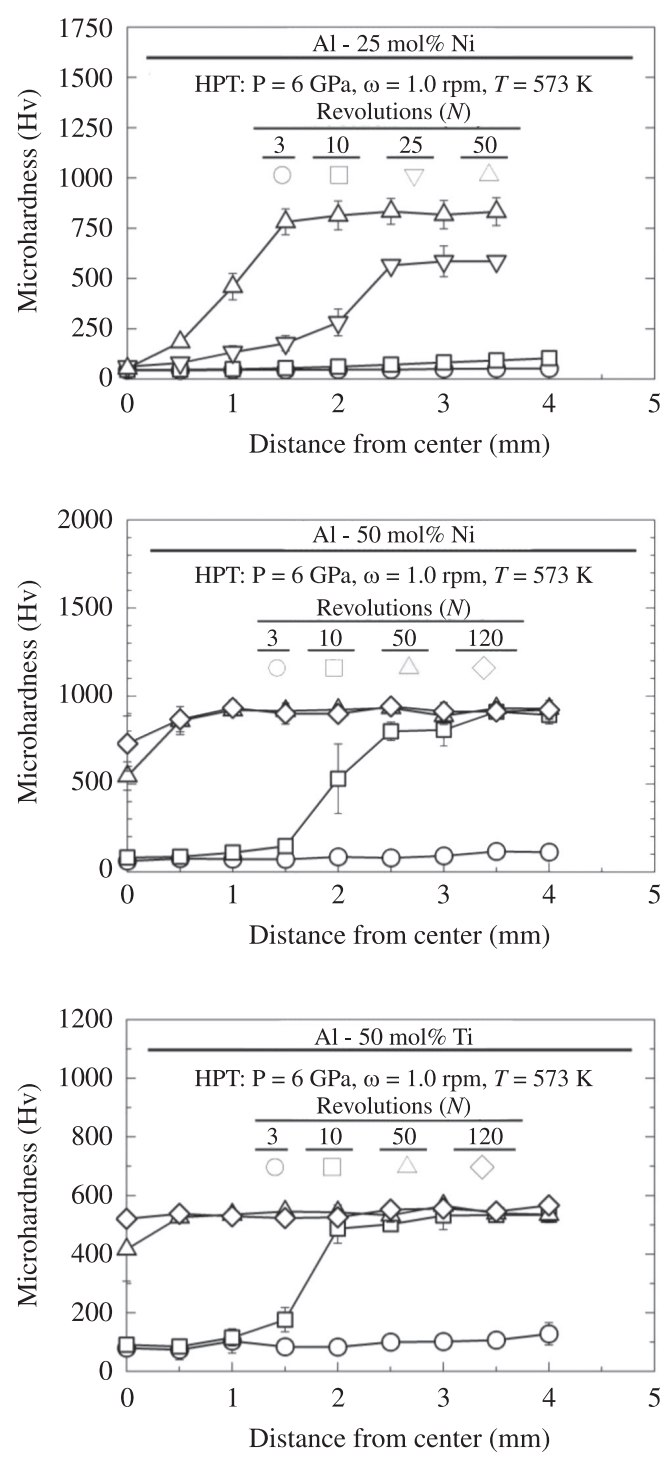

Figure 1. Vickers microhardness plotted against distance from disc center for (a) Al- 25\% Ni, (b) Al- 50\% Ni and (c) Al- 50\% Ti samples processed by HPT for various numbers of turns. 
full width at half maximum in the XRD patterns increases significantly with torsional straining using HPT, indicating the occurrence of lattice strains, dislocations generation and grain fragmentation during the HPT processing.

TEM micrographs including SAED patterns are shown in Figure 3 for the Al- 25\% Ni samples after HPT, where

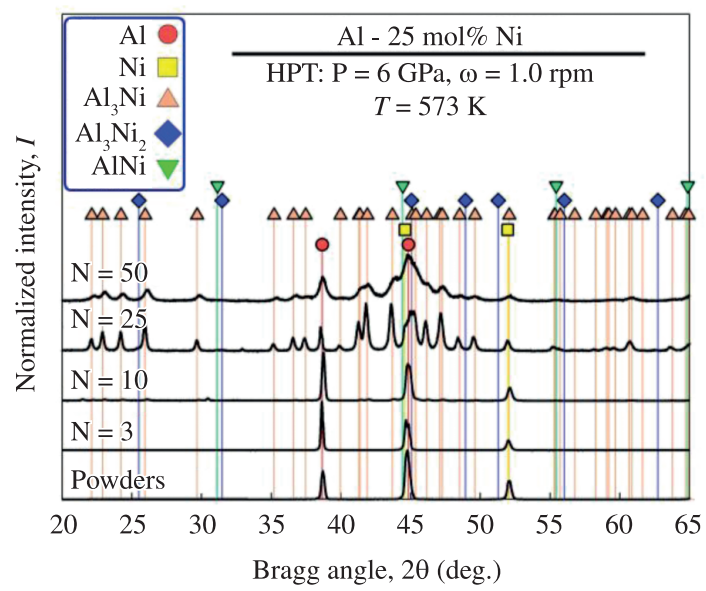

(a)

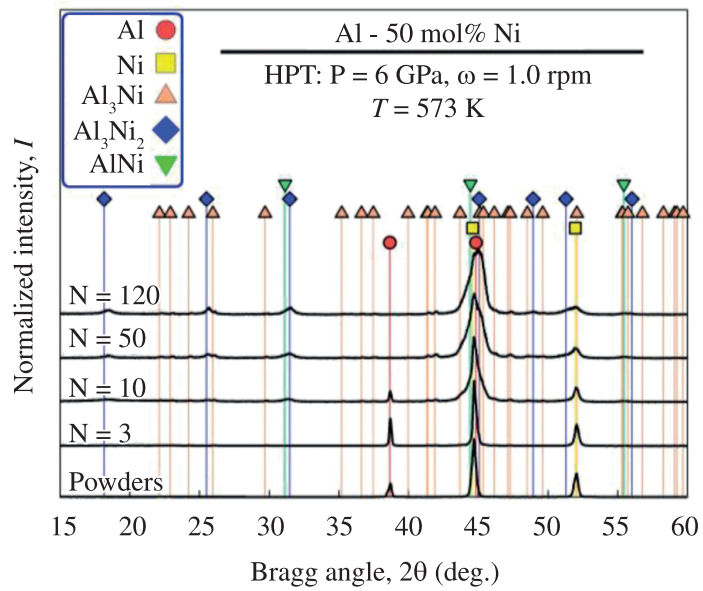

(b)

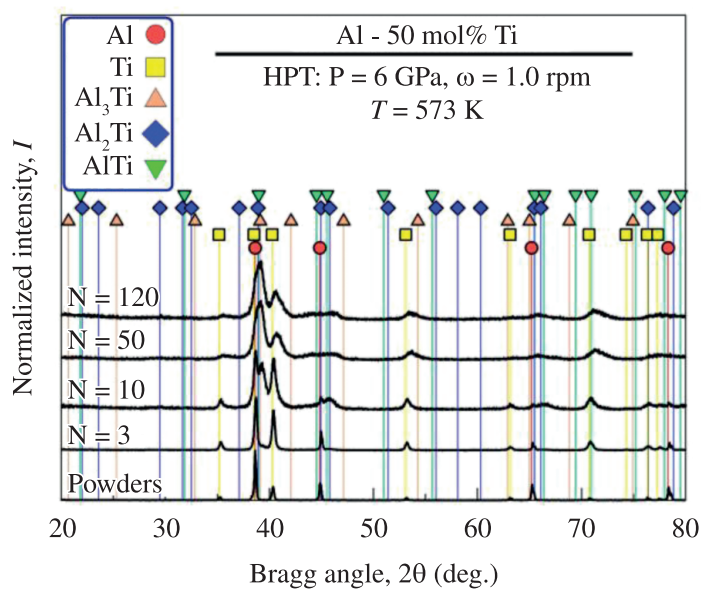

(c)

Figure 2. XRD profiles for (a) Al- $25 \% \mathrm{Ni}$, (b) Al- $50 \% \mathrm{Ni}$ and (c) Al$50 \%$ Ti samples processed by HPT for various numbers of turns. the bright-field images are on the left, the SAED patterns are in the inset at the center and the dark-field images taken with the diffracted beams indicated by the arrows in the SAED patterns are on the right. The micrographs and the corresponding SAED patterns were taken from four samples subjected to different numbers of turns: (a) $N=3$, (b) $N=10$, (c) $N=25$ and (d) $N=50$.

Observation shows that the microstructure corresponding to Figure 3 a consists of large grains with an average grain size of $\sim 2500 \mathrm{~nm}$. Although grains containing high dislocation density are locally visible within the microstructures as marked $\mathbf{A}$, few dislocations are visible within most of the grains with the grain boundaries well-defined in (a). It is noted that these microstructural features are typical of microstructures after processing by HPT at high homologous temperatures ${ }^{4,10}$. With increasing the shear stain, the grains are refined to the submicrometer level as in Figure $3 \mathrm{~b}$ and many $\mathrm{Al}_{3} \mathrm{Ni}$ nanograins as marked $\mathbf{B}$ are visible within the microstructures. In Figure $3 \mathrm{c}$ the grain size is reduced to the
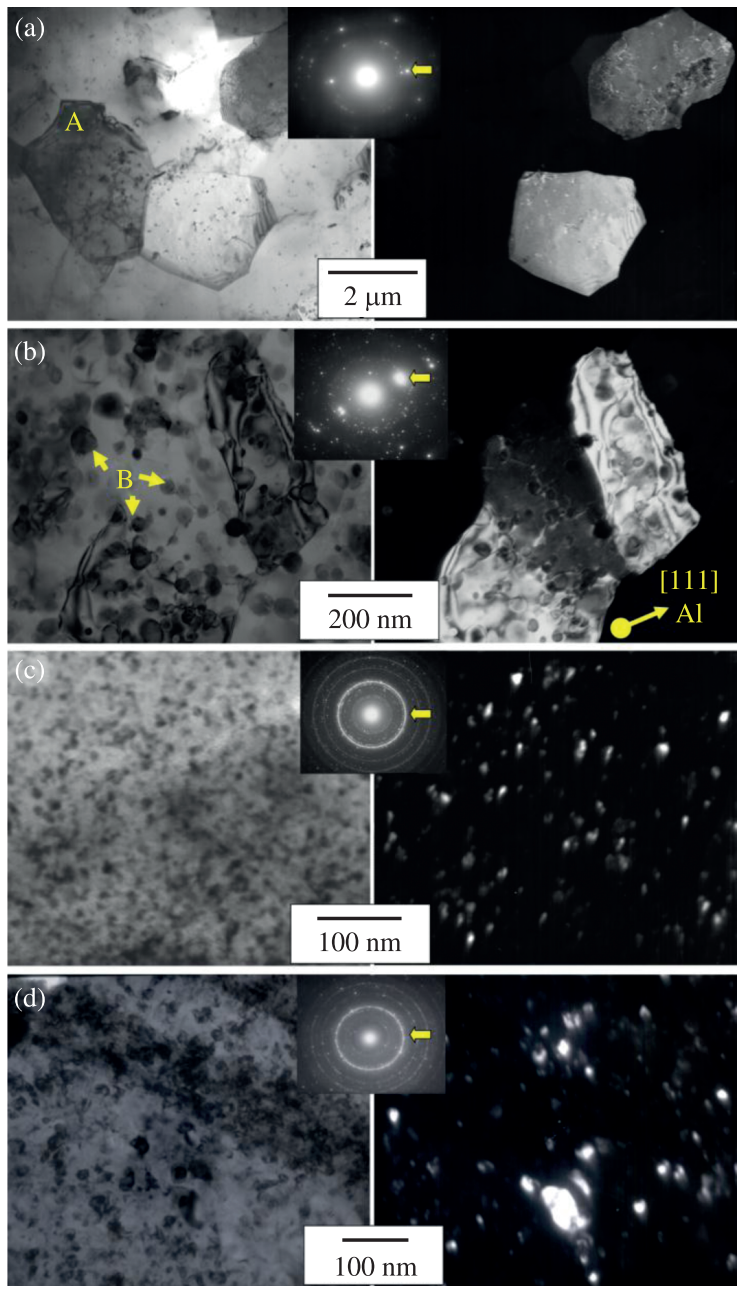

Figure 3. TEM bright-field images (left), SAED patterns (center) and dark-field images taken with diffracted beams indicated by arrows in SAED patterns (right) for Al- 25\% Ni samples processed for (a) 3, (b) 10, (c) 25 and (d) 50 turns. 
nanometer level and the ill-defined grain boundaries increase the misorientation angles because the SAED analysis now exhibits a ring pattern. In Figure $3 d$, the grain size reaches $\sim 40 \mathrm{~nm}$ and the grain boundaries appear to be better defined. The ring pattern from the SAED analysis indicates that the nanograins are separated by high angles of misorientations at the steady state.

The grain size of $\sim 40 \mathrm{~nm}$ is much smaller than those of the HPT-processed pure metals ${ }^{4,10,16,26}$ and many alloys ${ }^{3,5,6,9}$, but well comparable with those of HPT-processed intermetallics ${ }^{39,40}$, ceramics ${ }^{21}$, lattice softened alloys ${ }^{8}$ and semi-metals such as $\mathrm{Si}^{19}$. The formation of nanograins can be attributed to two main reasons: first, the presence of a second phase blocks the dislocations motion and grain boundaries movement, and second, the in-situ formed intermetallics have strong covalent bonding. For the latter, it was reported that the grain size in materials with covalent bonding is significantly reduced to the nanometer level by $\mathrm{HPT}^{41}$. The application of HPT to intermetallics as well as other materials with covalent bonding results in formation of a heterogeneous microstructure composed of nanograins and submicrometer grains $\mathrm{s}^{39,40}$, whereas the grain size distribution is reasonably uniform after in situ production with HPT $^{33}$. This is an important advantage of in-situ production of nanograined intermetallics by HPT.

High-resolution TEM images and corresponding diffractograms obtained by fast Fourier transform (FFT) analyses are shown in Figure 4 for the Al- 50\% Ni sample processed by HPT for 50 turns. The FFT analyses show that (a), (b) and (c) correspond to $\mathrm{Ni}, \mathrm{Al}_{3} \mathrm{Ni}$ and $\mathrm{Al}_{3} \mathrm{Ni}_{2}$, respectively. This characterization is well consistent with the XRD analyses. The average grain size for this sample is $\sim 30 \mathrm{~nm}$ which is slightly smaller than the steady-state grain size of the HPT-processed Al- 25\% Ni sample. It should be noted that this sample after annealing at $673 \mathrm{~K}$ transform to $\sim 100 \%$ AlNi intermetallic with an average grain size of $\sim 50 \mathrm{~nm}^{33}$.

Microstructures are shown in Figure 5 for the Al- 50\% Ti sample processed for 50 turns, where (a) is a TEM bright-field image including the corresponding SAED pattern, (b) is a dark-field image taken with the diffracted beams indicated by the arrow in the SAED pattern, (c) is a high resolution image and the corresponding difractogram, and (d) is a reconstructed lattice images of the square region in (c) obtained by inverse FFT, which corresponds to either $\mathrm{Al}$ or TiAl. Note that the micrographs were taken on the sample at the steady state where the hardness remains unchanged with straining. The TEM characterization indicates several important points.

First, the bright- and dark-field images show that the nanograins form after HPT processing with an average grain size of $\sim 20 \mathrm{~nm}$. It should be noted that this sample transforms to $\sim 100 \%$ TiAl after annealing at $873 \mathrm{~K}$ with an average grain size of $\sim 100 \mathrm{~nm}$ with a large fraction of nanotwins ${ }^{34}$. Second, the SAED pattern exhibits a complete form of rings, indicating that the microstructure consists of very small grains having high angles of misorientations. Third, the high-resolution image also shows the formation of nanograins. Fourth, examination of the lattice image clearly shows that there is at least one edge dislocation
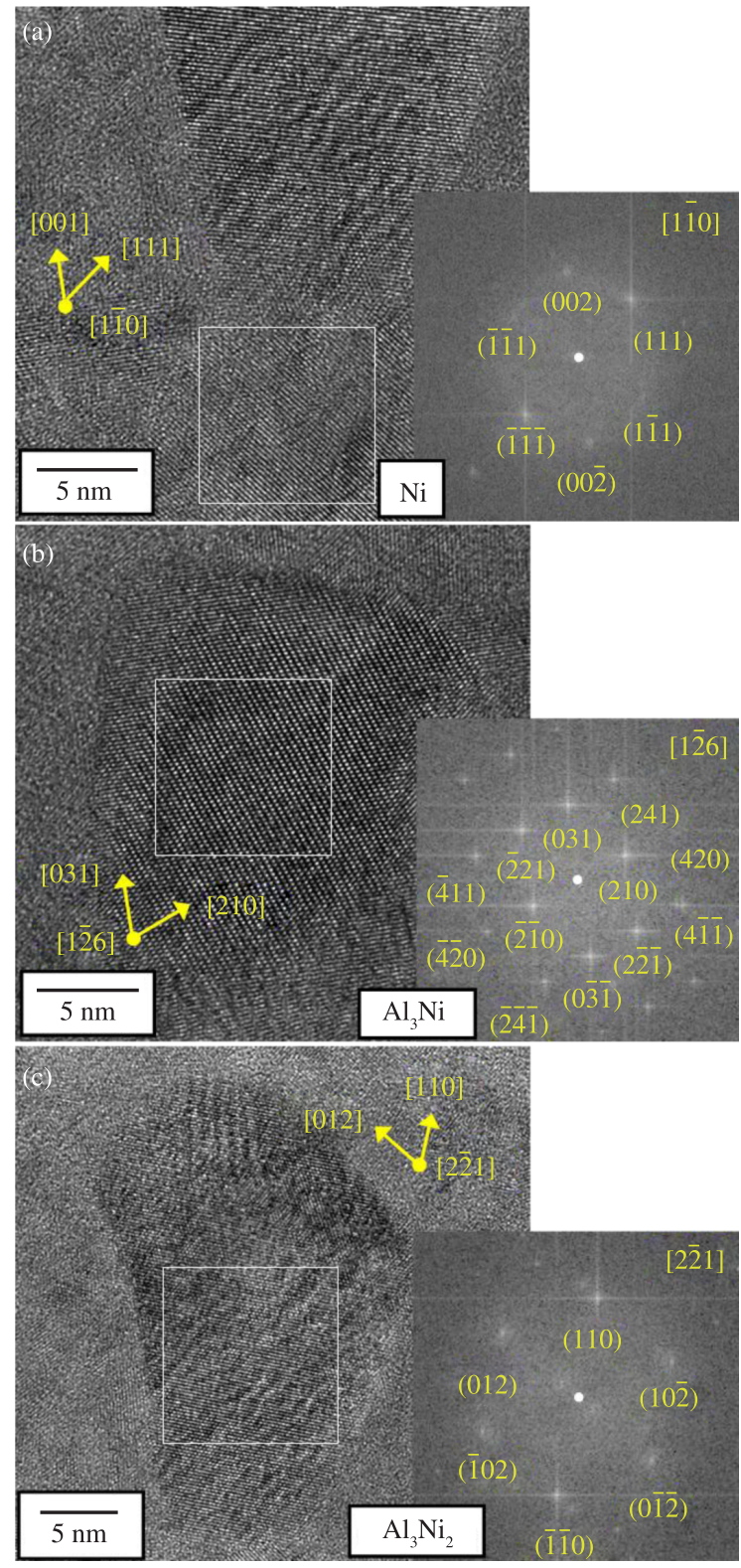

Figure 4. High resolution image (left) and corresponding FFT analysis (right) from square regions which correspond to (a) $\mathrm{Ni}$, (b) $\mathrm{Al}_{3} \mathrm{Ni}$ and (c) $\mathrm{Al}_{3} \mathrm{Ni}_{2}$ for $\mathrm{Al}-50 \% \mathrm{Ni}$ samples processed by HPT for 50 turns.

in the interior of the grain. Considering the grain size of $\sim 20 \mathrm{~nm}$, an estimation of the minimum dislocation density results in $3.2 \times 10^{15} \mathrm{~m}^{-2}$, provided that at least a single dislocation exists in each nanograin. It turns out that such a high dislocation density within the nanograins, which is consistent with the peak broadening in the XRD patterns, is comparable to that in HPT-processed pure metals ${ }^{42}$, alloys ${ }^{6}$ and ceramics ${ }^{21}$.

Two samples after processing by HPT and after the HPT processing with subsequent annealing were subjected to micropillar compression testing at room temperature with a pillar size of $\sim 4 \times 4 \times 12 \mu \mathrm{m}^{3}$. The micropillar 

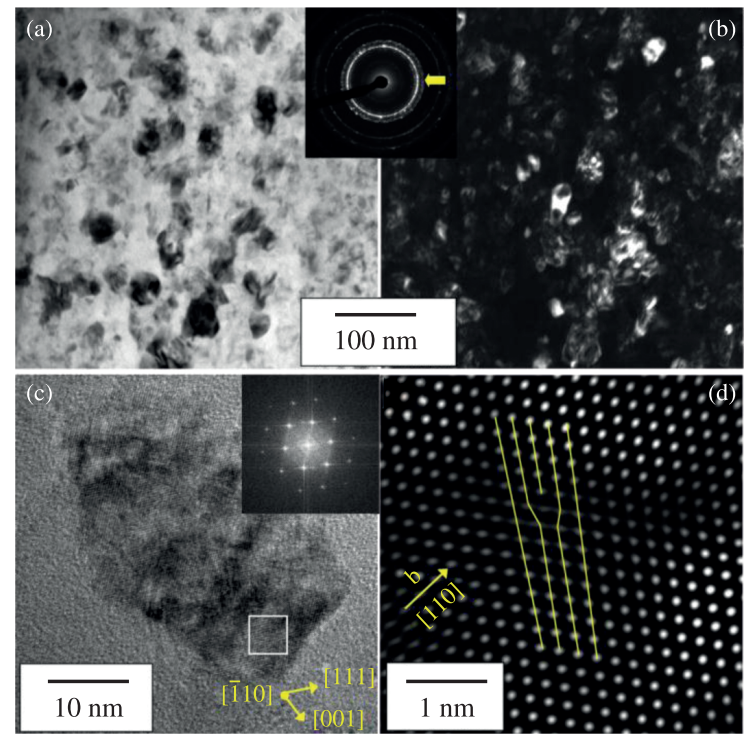

Figure 5. TEM micrographs of Al- 50\% Ti sample after HPT processing for 50 turns. (a) bright-field image and corresponding SAED pattern, (b) dark-field image taken with diffracted beams indicated by arrow in SAED patterns, (c) high resolution image and corresponding FFT analysis (d) reconstructed lattice image of square region in (c) after inverse FFT analysis, showing presence of $\{111\}<110>$ edge dislocation.

compression test was used in this study because of several reasons. First, despite many papers regarding the tensile properties of HPT-processed materials $2,7,9,12,16,23,26,27$, there are limited reports regarding their compression properties ${ }^{34}$. Second, since some fractions of micropores are formed during consolidation by $\mathrm{HPT}^{33,34}$, the micropillar was used to minimize the effect of micropores on the mechanical properties. Third, the micropillars are appropriate to investigate the deformation mechanism ${ }^{43}$. Figure 6 shows representative stress-strain curves of the samples. The sample after HPT processing but before annealing, which consists of certain fractions of $\mathrm{Ti}, \mathrm{TiAl}_{2}$ and $\mathrm{TiAl}$, exhibits a high yield strength as $\sim 1.7 \mathrm{GPa}$ but a limited plasticity as $2 \%$. The sample after HPT processing and annealing, which is composed only of TiAl, exhibits a plasticity as high as $\sim 23 \%$. The yield strength is also significantly enhanced to the level as high as $\sim 3 \mathrm{GPa}$ and this strength is $4-10$ times higher than those for micropillars of TiAl single crystals ${ }^{43}$. It should be noted that the sample after annealing had a bimodal microstructure composed of nanograins and submicrometer grains with an average grain size of $\sim 100 \mathrm{~nm}$ with a high density of nanotwins with an average twin width of $\sim 9 \mathrm{~nm}$.

Figure 7 shows the TiAl micropillars (a) before compression test and (b) after compression test. It is evident that the pillar is deformed plastically with an estimated uniform plasticity of $\sim 19 \%$ which is well consistent with the compression test. The high uniform plasticity may be attributed to the two microstructural futures: one for bimodal microstructure formation composed of nanograins and submicrometer grains and the other for nanotwins formation as discussed earlier ${ }^{34}$.

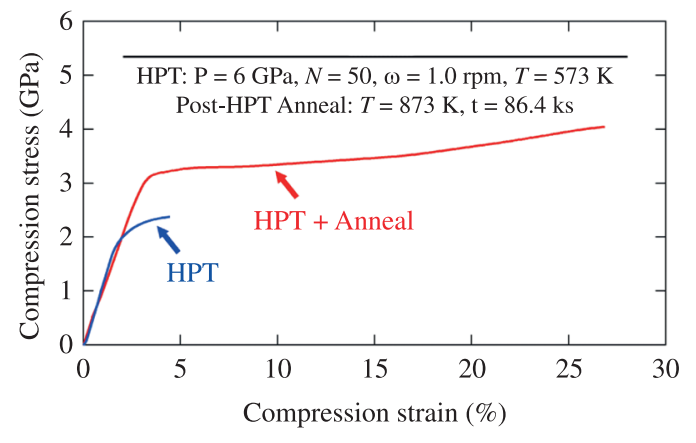

Figure 6. Nominal stress versus nominal strain curves for $\mathrm{Al}-50 \% \mathrm{Ti}$ samples after HPT processing for 50 turns and after HPT processing and annealing at $873 \mathrm{~K}$ for 1 hour. Micropillar compression tests were carried out at nominal stress rate of $10 \mathrm{MPa} / \mathrm{s}$, corresponding to initial strain rate of $10^{-4} \mathrm{~s}^{-1}$.

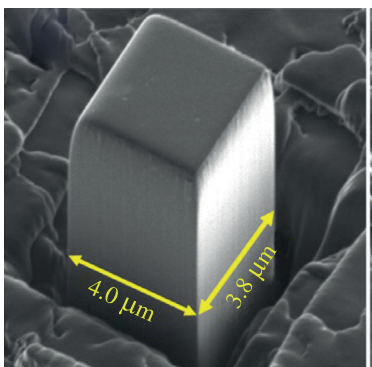

(a)

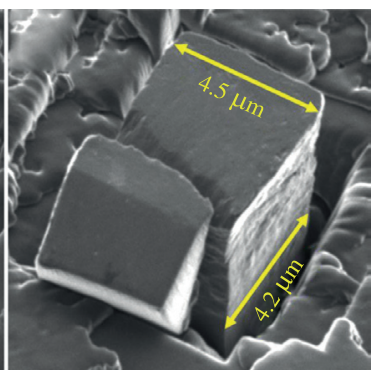

(b)
Figure 7. Appearance of pillars for Al- 50\% Ti sample processed by HPT for 50 turns. (a) before compression and (b) after compression observed by SEM.

\section{Conclusions}

- Micropowder mixtures of Al- 25\% Ni, Al- 50\% $\mathrm{Ni}$ and Al- 50\% Ti were consolidated by HPT at a temperature of $573 \mathrm{~K}$;

- Large fractions of intermetallics such as $\mathrm{Al}_{3} \mathrm{Ni}$, $\mathrm{Al}_{3} \mathrm{Ni}_{2}, \mathrm{TiAl}_{3}, \mathrm{TiAl}_{2}$ and TiAl were formed because of enhanced diffusivity;

- Along with the formation of intermetallics, the grain size was reduced to $20-40 \mathrm{~nm}$ and the hardness was increased to $550-920 \mathrm{Hv}$;

- The compression strength was $\sim 1.7 \mathrm{GPa}$ with $\sim 2 \%$ ductility in the Al- 50\% Ti samples processed by HPT, but increased to $\sim 3 \mathrm{GPa}$ with the ductility as high as $\sim 23 \%$ after subsequent annealing.

\section{Acknowledgements}

One of the authors (AA) thanks the Indonesian Directorate of Higher Education Program (DIKTI) for a doctoral scholarship. The author (KE) acknowledges the Japan Society for Promotion of Science (JSPS) for a postdoctoral scholarship. This work was supported in part by the Light Metals Educational Foundation of Japan, in part by a Grant-in-Aid for Scientific Research from the MEXT, Japan, in Innovative Areas "Bulk Nanostructured Metals" and in part by Kyushu University Interdisciplinary Programs in Education and Projects in Research Development (P\&P). 


\section{References}

1. Bridgman PW. Effects of high shearing stress combined with high hydrostatic pressure. Physical Review. 1935; 48(10):825-847. http://dx.doi.org/10.1103/PhysRev.48.825

2. Valiev RZ, Estrin Y, Horita Z, Langdon TG, Zehetbauer MJ and Zhu YT. Producing bulk ultrafine-grained materials by severe plastic deformation. Journal of the Minerals, Metals and Materials Society. 2006; 58(4):33-39. http://dx.doi. org/10.1007/s11837-006-0213-7

3. Valiev RZ, Krasilnikov NA and Tsenev NK. Plastic deformation of alloys with submicron-grained structure. Materials Science and Engineering A. 1991; 137:35-40. http:// dx.doi.org/10.1016/0921-5093(91)90316-F

4. Kawasaki M, Figueiredo RB and Langdon TG. An investigation of hardness homogeneity throughout disks processed by high-pressure torsion. Acta Materialia. 2011; 59(1):308-316. http://dx.doi.org/10.1016/j.actamat.2010.09.034

5. Tugcu T, Sha G, Lia XZ, Trimby P, Xia JH, Murashkin $\mathrm{MY}$ et al. Enhanced grain refinement of an $\mathrm{Al}-\mathrm{Mg}-\mathrm{Si}$ alloy by high-pressure torsion processing at $100{ }^{\circ} \mathrm{C}$. Materials Science and Engineering A. 2012; 552:415-418. http://dx.doi. org/10.1016/j.msea.2012.05.063

6. Yoon EY, Lee DJ, Kim TS, Chae HJ, Jenei P, Gubicza J et al. Microstructures and mechanical Properties of $\mathrm{Mg}-\mathrm{Zn}-\mathrm{Y}$ alloy consolidated from gas-atomized powders using high-pressure torsion. Journal of Materials Science. 2012; 47(20):7117-7123. http://dx.doi.org/10.1007/s10853-012-6408-0

7. Valiev RZ, Alexandrov IV, Zhu YT and Lowe TC. Paradox of strength and ductility in metals processed by severe plastic deformation. Journal of Materials Research. 2002; 17(1):5-8. http://dx.doi.org/10.1557/JMR.2002.0002

8. Edalati K, Toh T, Furuta T, Kuramoto S, Watanabe M and Horita Z. Development of ultrahigh strength and high ductility in nanostructured iron alloys with lattice softening and nanotwins. Scripta Materialia. 2012; 67(5):511-514. http:// dx.doi.org/10.1016/j.scriptamat.2012.06.019

9. Zhang P, An XH, Zhang ZJ, Wu SD, Li SX, Zhang ZF et al. Optimizing strength and ductility of $\mathrm{Cu}-\mathrm{Zn}$ alloys through severe plastic deformation. Scripta Materialia. 2012; 67(11):871-874. http://dx.doi.org/10.1016/j.scriptamat.2012.07.040

10. Edalati K, Imamura K, Kiss $\mathrm{T}$ and Horita Z. Equal-channel angular pressing and high-pressure torsion of pure copper: evolution of electrical conductivity and hardness with strain. Materials Transactions. 2012; 53(1):123-127. http://dx.doi. org/10.2320/matertrans.MD201109

11. Valiev RZ, Semenova IP, Jakushina E, Latysh VV, Rack H, Lowe TC et al. Nanostructured SPD Processed Titanium for Medical Implants. Materials Science Forum. 2008; 584-586:49-54. http://dx.doi.org/10.4028/www.scientific.net/MSF.584-586.49

12. Valiev RZ and Langdon TG. Achieving exceptional grain refinement through severe plastic deformation: New approaches for improving the processing technology. Metallurgical Materials Transactions A. 2011; 42(10):2924-2951. http:// dx.doi.org/10.1007/s11661-010-0556-0

13. Yilmazer H, Niinomi M, Nakai M, Hieda J, Todaka Y, Akahori $\mathrm{T}$ et al. Heterogeneous structure and mechanical hardness of biomedical $\beta$-type Ti-29Nb-13Ta-4.6Zr subjected to high-pressure torsion. Journal of the Mechanical Behaviour of Biomedical Materials. 2012; 10:234-245. http://dx.doi. org/10.1016/j.jmbbm.2012.02.022

14. Faghihi S, Li D and Szpunar JA. Tribocorrosion behaviour of nanostructured titanium substrates processed by high-pressure torsion. Nanotechnology. 2010; 21(48):485703. http://dx.doi. org/10.1088/0957-4484/21/48/485703

15. Wang CT, Gao N, Gee MG, Wood JK and Langdon TG. Processing of an ultrafine-grained titanium by high-pressure torsion: an evaluation of the wear properties with and without a TiN coating. Journal of the Mechanical Behaviour of Biomedical Materials. 2013; 17:166-175. http://dx.doi. org/10.1016/j.jmbbm.2012.08.018

16. Edalati K, Yamamoto A, Horita $Z$ and Ishihara T. High-pressure torsion of pure magnesium: evolution of mechanical properties, microstructures and hydrogen storage capacity with equivalent strain. Scripta Materialia. 2011; 64(9):880-883. http://dx.doi. org/10.1016/j.scriptamat.2011.01.023

17. Revesz A, Kis-Toth A, Varoa LK, Schafler E, Bakonvi I and Spassov T. Hydrogen storage of melt-spun amorphous $\mathrm{Mg}_{65} \mathrm{Ni}_{20} \mathrm{Cu}_{5} \mathrm{Y}_{10}$ alloy deformed by high-pressure torsion. International Journal of Hydrogen Energy. 2012; 37(7):57695776. http://dx.doi.org/10.1016/j.ijhydene.2011.12.160

18. Krystian M, Setman D, Mingler B, Krexner G and Zehetbauer MJ. Formation of superabundant vacancies in nano-Pd-H generated by high-pressure torsion. Scripta Materialia. 2010; 62(1):49-52. http://dx.doi.org/10.1016/j. scriptamat.2009.09.025

19. Ikoma Y, Hayano K, Edalati K, Saito K, Guo Q and Horita Z. Phase transformation and nanograin refinement of silicon by processing through high-pressure torsion. Applied Physics Letters. 2012; 101(12):121908. http://dx.doi. org/10.1063/1.4754574

20. Straumal BB, Gornakova AS, Mazilkin AA, Fabrichnaya $\mathrm{OB}$, Kriegel MJ, Baretzky B et al. Phase transformations in the severely plastically deformed $\mathrm{Zr}-\mathrm{Nb}$ alloys. Materials Letters. 2012; 81:225-228. http://dx.doi.org/10.1016/j. matlet.2012.04.153

21. Edalati K, Toh S, Ikoma Y and Horita Z. Plastic deformation and allotropic phase transformations in zirconia ceramics during high-pressure torsion. Scripta Materialia. 20111; 65(11):974977.

22. Straumal BB, Gornakova AS, Fabrichnaya OB, Kriegel MJ, Mazilkin AA, Baretzky B et al. Effective temperature of high pressure torsion in $\mathrm{Zr}-\mathrm{Nb}$ alloys. High Temperature Materials and Processes. 2012; 31(4-5):339-350.

23. Zhilyaev AP, Gimazov AA, Raab GI and Langdon TG. Using high-pressure torsion for the cold-consolidation of copper chips produced by machining. Materials Science and Engineering A. 2008; 486(1-2):123-128. http://dx.doi.org/10.1016/j. msea.2007.08.070

24. Zhilyaev AP, Swaminathan S, Gimazov AA, McNelly TR and Langdon TG. An evaluation of microstructure and microhardness in copper subjected to ultra-high strains. Journal of Materials Science. 2008; 43(23-24):7451-7456. http:// dx.doi.org/10.1007/s10853-008-2714-y

25. Sort J, Zhilyaev A, Zielinska M, Nogues J, Surinach S, Thibault $\mathrm{J}$ et al. Microstructural effects and large microhardness in cobalt processed by high pressure torsion consolidation of ball milled powders. Acta Materialia. 2003; 51(20):6385-6393. http:// dx.doi.org/10.1016/j.actamat.2003.08.006

26. Alexandrov IV, Zhu YT, Lowe TC, Islamgaliev RK and Valiev RZ. Microstructures and properties of nanocomposites obtained through SPTS consolidation of powders. Metallurgical Materials Transactions A. 1998; 29(9):2253-2260. http:// dx.doi.org/10.1007/s11661-998-0103-4

27. Yoon EY, Lee DJ, Ahn DH, Lee ES and Kim HS. Mechanical properties and thermal stability of bulk $\mathrm{Cu}$ cold consolidated from atomized powders by high-pressure torsion. Journal of 
Materials Science. 2012; 47(22):7770-7776. http://dx.doi. org/10.1007/s10853-012-6569-x

28. Sauvage X, Jessner P, Vurpillot F and Pippan R. Scripta Materialia. Nanostructure and properties of a $\mathrm{Cu}-\mathrm{Cr}$ composite processed by severe plastic deformation. Scripta Materialia. 2008; 58(12):1125-1128. http://dx.doi. org/10.1016/j.scriptamat.2008.02.010

29. Pippan R, Scheriau S, Taylor A, Hafok M, Hohenwarter $\mathrm{A}$ and Bachmaier A. Saturation of fragmentation during severe plastic deformation. Annual Review of Materials Research. 2010; 40: 319-343. http://dx.doi.org/10.1146/ annurev-matsci-070909-104445

30. Zhilyaev AP and Langdon TG. Using high-pressure torsion for metal processing: Fundamentals and applications. Progress in Materials Science. 2008; 53(6):893-979. http://dx.doi. org/10.1016/j.pmatsci.2008.03.002

31. Horita Z, editor. Production of mutifunctional materials using severe plastic deformation. In: Proceedings of International Symposium on Giant Straining Process for Advanced Materials (GSAM2010); 2010; Fukuoka. Fukuoka: Kyushu University Press; 2011.

32. Zehetbauer M, Grossinger R, Krenn H, Krystian M, Pippan $\mathrm{R}, \operatorname{Rogl} \mathrm{P}$ et al. Bulk Nanostructured Functional Materials By Severe Plastic Deformation. Advanced Engineering Materials. 2012; 12(8):692-700. http://dx.doi.org/10.1002/ adem.201000119

33. Edalati K, Toh S, Watanabe $\mathrm{M}$ and Horita Z. In-situ production of bulk intermetallic-based nanocomposites and nanostructured intermetallics by high-pressure torsion. Scripta Materialia. 2012; 66(1):386-389. http://dx.doi.org/10.1016/j. scriptamat.2011.11.039

34. Edalati K, Toh S, Iwaoka H, Watanabe M, Horita Z, Kashioka $\mathrm{D}$ et al. Ultrahigh strength and high plasticity in TiAl intermetallics with bimodal grain structure and nanotwins. Scripta Materialia. 2012; 67(10):814-817. http://dx.doi. org/10.1016/j.scriptamat.2012.07.030

35. Fujita T, Horita Z and Langdon TG. Characteristics of diffusion in Al-Mg alloys with ultrafine grain sizes. Philosophical
Magazine A. 2002; 82(11):2249-2262. http://dx.doi. org/10.1080/01418610208235736

36. Divinski SV, Reglitz G, Rosner H, Estrin Y and Wilde G. Ultra-fast diffusion channels in pure Ni severely deformed by equalchannel angular pressing. Acta Materialia. 2011; 59(5):19741985. http://dx.doi.org/10.1016/j.actamat.2010.11.063

37. Setman D, Schafler E, Korznikova E and Zehetbauer MJ. The presence and nature of vacancy type defects in nanometals detained by severe plastic deformation. Materials Science and Engineering A. 2008; 493(1-2):116-122. http://dx.doi. org/10.1016/j.msea.2007.06.093

38. Mehrer H. Numerical Data and Functional Relationships in Science and Technology, Diffusion in Solid Metals and Alloys. Berlin: Springer-Verleg; 1990. v. 26. http://dx.doi.org/10.1007/ b37801

39. Ciuca O, Tsuchiya K, Yokoyama Y, Todaka Y and Umemoto M. Heterogeneous Process of Disordering and Structural Refinement in $\mathrm{Ni}_{3} \mathrm{Al}$ during Severe Plastic Deformation by High-Pressure Torsion. Materials Transactions 2010; 51(1):14-22. http:// dx.doi.org/10.2320/matertrans.MB200915

40. Rentenberger C, Waitz T and Karnthaler HP. Formation and structures of bulk nanocrystalline intermetallic alloys studied by transmission electron microscopy. Materials Science and Engineering A. 2007; 462(1-2):283-288. http://dx.doi. org/10.1016/j.msea.2006.03.151

41. Edalati $\mathrm{K}$ and Horita Z. High-pressure torsion of pure metals: Influence of atomic bond parameters and stacking fault energy on grain size and correlation with hardness. Acta Materialia. 2011; 59(17):6831-6836. http://dx.doi. org/10.1016/j.actamat.2011.07.046

42. Hegedus Z, Gubicza J, Kawasaki M, Chinh NQ, Fogarassy Z and Langdon TG. Microstructure of low stacking fault energy silver processed by different routes of severe plastic deformation. Journal of Alloys and Compounds. 2012; 536S(1):S190-S193. http://dx.doi.org/10.1016/j.jallcom.2011.10.070

43. Fujimura K, Kishida K, Tanaka K and Inui H. Compression of micropillars of TiAl coexisting with $\mathrm{Ti}_{3} \mathrm{Al}$. Materials Research Socity Symposium Proceeding. 2011; 1295:201-206. 